ASSN:1991-8178
EISSN: $2309-8414$
DOI: $10.22587 /$ ajbas.2017.11.15.8
Journal home page: www.ajbasweb.com

\title{
Mothers' Coping Strategies in Preparing for the Discharge of Low Birth Weight Infants from a Perinatology Ward
}

\author{
${ }^{1}$ Eviana S Tambunan, ${ }^{1}$ Hadi Pratomo, ${ }^{1}$ Ella Nurlaella Hadi, ${ }^{2}$ Yeni Rustina \\ ${ }^{1}$ Doctoral student, Doctor of Public Health Study Program, Faculty of Public Health, Universitas Indonesia, Depok, West Java, Indonesia. \\ ${ }^{1}$ Professor, Dr.PH, Department of Health Education and Behavioral Sciences, Faculty of Public Health, Universitas Indonesia, Depok, \\ West Java, Indonesia. \\ ${ }^{1}$ Lecturer and Researcher, Dr, Department of Health Education and Behavioral Sciences, Faculty of Public Health, Universitas Indonesia, \\ Depok, West Java, Indonesia. \\ ${ }^{2}$ Lecturer and Researcher, PhD, Pediatric Nursing Science Department, Faculty of Nursing, Universitas Indonesia, Depok, West Java, \\ Indonesia.
}

\author{
Address For Correspondence: \\ Hadi Pratomo, Department of Health Education and Behavioral Sciences, Faculty of Public Health, Universitas Indonesia, Depok, West \\ Java, Indonesia. \\ Email: hadi.pratomo@ui.ac.id
}

\section{ARTICLE INFO}

Article history:

Received 12 October 2017

Accepted 22 December 2017

Available online 31 December 2017

Keywords:

coping strategies, mother stress, low birth weight infant

\begin{abstract}
A B S T R A C T
Background: Low birth weight infants are born weighing less than 2500 grams. The chance of life increases with the advancement of technology through intensive care in the perinatology ward. High medical needs during infant care, duration of care, and lack of knowledge about the condition of the infant are factors that causes stress on mothers to bring the infant home. Mother may feel incompetence in caring for the infant at home. Greater stress occurs among mothers who are lack of proper coping skills. Objective: This study aimed to appraise mothers' coping strategies for dealing with stress related to the discharge preparations of a low birth weight (LBW) infant. Sixty mothers of LBW infants hospitalized in a perinatology ward participated in this descriptive-correlational study. They were selected using a convenience sampling method. Data were collected using a structured questionnaire of the Stress and Coping Strategies Scale, and the questionnaire was tested for validity and reliability (Cronbach's alpha: 0.72). Descriptive and inferential statistics, including the Pearson's correlation test, were applied to analyze the data using SPSS. Results: Most mothers $(86 \%)$ used coping strategies focused on emotions, and $78 \%$ reported using ones that focus on solving problems. There was a significant correlation among the infant's length of hospitalization (p. 0.024) and history of hyperbilirubinemia (p. 0.007) with a mother's coping strategy. We also found a strong significant correlation between mothers' stress and coping strategies (r. -0.641 ; p. < 0.001). Conclusion: This study indicate that stress scores are significantly associated with coping strategies: the higher the score, the lower the mother's coping ability. Developing a maternal coping strategy that focuses on problem solving will increase mother's confidence in preparing for the discharge of LBW infants from perinatology ward and able to care for the baby at home. We recommend that nurses help mothers develop coping strategies with a focus on problem solving through family involvement and educational care for LBW infants.
\end{abstract}

\section{INTRODUCTION}

The survival rate of low birth weight (LBW) infants has seen a significant rise over the last three decades. Newborns of 22 weeks' gestational age now have a greater chance of surviving, thanks to technological advancements in intensive care (Altimier \& White, 2014). These advancements allow stable LBW infants to be discharged from the hospital before achieving a weight of 2500 grams. Still, the moment of discharge is a critical period for parents, as they move from the hospital milieu to the home and they become fully responsible

Open Access Journal

\section{Published BY AENSI Publication}

(C) 2017 AENSI Publisher All rights reserved

This work is licensed under the Creative Commons Attribution International License (CC BY).

http://creativecommons.org/licenses/by/4.0/

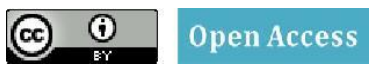

To Cite This Article: Eviana S Tambunan, Hadi Pratomo, Ella Nurlaella Hadi, Yeni Rustina, Mothers' Coping Strategies in Preparing for the Discharge of Low Birth Weight Infants from a Perinatology Ward. Aust. J. Basic \& Appl. Sci., 11(15): 54-63, 2017 
for their infant's care. Though parents are eager to do this, many do not feel completely ready when the babies are finally sent home (Jefferies, 2016). Preterm birth and prolonged hospitalization are known family stressors and risk factors for subsequent family dysfunction. In addition, birth defects and disabling conditions are also risk factors. Other stress-related factors refer to the mother, such as a lower educational level, a lack of social support, marital instability, and fewer prenatal care visits (Segre, McCabe, Chuffo-Siewert, \& O’Hara, 2015; Welch et al., 2016)

Several studies have indicated that mothers experience anxiety and apprehension at the time of NICU discharge, when they make the transition from being supported by neonatal staff to going home and providing full infant care on their own. Zanardo, Freato, and Zacchello (2003) examined mothers' anxiety levels at the time of discharge and found them higher among mothers of neonatal intensive care unit (NICU) infants when compared to those of healthy infants. In a study of Latino mothers, Miquel-Verges, Donohue, and Boss (2011) observed that mothers expressed a general sense of worry about their infant's medical condition and development, but could not identify a specific risk factor that concerned them as the anticipated discharge date neared. Both studies showed that stress causes a lack of parental readiness for perinatology ward discharge, therefore mother should deal with the stress, and they should develop coping strategy to solve the stress.

Until now, there is no literature specifically evaluating the coping strategies of mothers in preparing for the discharge of LBW infants from perinatology ward in Central Jakarta, Indonesia. However, there are a number of studies from other countries revealed that higher anxiety among mothers during the discharge process, especially when the mothers had no proper coping skills and social support system (Gigante et al., 2004; Nicolson et al., 2013; Ray, Escobar, and Lorch, 2010). The stress that occurs while in the hospital is likely due to the NICU situation, and stress may continue as the infant is being prepared of discharge from perinatology ward, the mother may feel unprepared to care for the infant at home. This, in turn, affects the mother's preferred coping strategies. Mothers with poor coping strategies experience greater psychological distress (Gangi et al., 2013). Parents, particularly mothers, should employ adaptive coping strategies to deal with the stress during the discharge process from perinatology wards (Olshtain-Mann \& Auslander, 2008). In dealing with stress, parents use coping strategies. Coping refers to one's cognitive and behavioral efforts to manage stress (Folkman \& Lazarus, 1985). Specific coping strategies serve to manage and alter stress (problem-focused coping) or regulate one's emotional response to stress (emotion-focused coping). It is important to ensure that mothers are well supported in the NICU to assume their parenting role in preparing for their infant transition from hospital to home

A critical point of this study is to appraise mothers' coping strategies for dealing with the stresses of discharge preparations for an LBW infant so it can be determined what interventions are needed for improving mother's coping skills.

\section{MATERIALS AND METHOD}

\section{Design and Sample:}

The study used a cross-sectional approach and was conducted between May and August 2017. The study population was mothers of neonates admitted to the perinatology ward of RSIA (Mother and Children Hospital) Budi Kemuliaan and RSUD (General Hospital) Tarakan of Central Jakarta, Indonesia. Based on a similar study conducted by Klebanov, Brooks-Gunn, and McCormick (2001), where the mean score for mothers who used active coping was 20.93, with a standard deviation of 4.71, we determined the sample size for this study. To achieve a power of .90 at .05 with an assumption for an expected coping score increase by $10 \%$, requires a minimum sample size of 57. Therefore, we investigated 60 mothers for our study. Inclusion criteria were mothers with a LBW infant with no congenital defects. Exclusion criteria were: a) mother's hospitalization, b) refusing to participate, and c) mothers; unavailability during the data collection period. We used a convenience sampling method.

Data were collected through structured, questionnaire-based interviews. The researchers conducted all interviews. After the interview was complete, participants received a small honorarium.

\section{Instrument:}

Data were collected using a three-part structured questionnaire investigating parent demographics, infant characteristics, and stress and coping strategies. The questionnaire was a modification of Folkman and Lazarus' (1985) Ways of Coping Questionnaire and Kenner and Lott's (1990) Transition Questionnaire. Thirty items about coping strategies came from the Ways of Coping Questionnaire, and eight items about stress came from the Transition Questionnaire. Selections were made in consultation with experts in psychology and child health. Furthermore, we tested the questionnaire on 30 respondents with situations similar to the study population. Measurements using the Pearson Product Moment revealed 13 invalid questions ( $\mathrm{r}$ result $<\mathrm{r}$ table), which were excluded. Then, we conducted a reliability test conducted on the valid items. Cronbach's alpha was calculated; the value for the questionnaire was 0.72 , indicating validity and reliability. The final questionnaire contains 25 
items, five on mothers' stress, seven on problem-oriented coping, and 13 emotion-oriented items. Scoring was based on a five-point Likert scale, from never (1) to always (5). Possible total scores ranged from 25 to 125. Higher coping scores, for positive questions, show a better ability to handle problems; the opposite is true for negative question items. Higher stress scores indicate increasingly severe stress. Parental stress levels were classified as low (1-1.9), moderate (2-3.9) and high (4-5) (Agrawal \& Gaur, 2017).

\section{Ethical Clearance and Subject Recruitment:}

After obtaining ethical approval from the hospitals' research ethics committees, the research team collected further data. The team consisted of principal investigators, team members, and data collectors (enumerators). The enumerators were nurses or midwives not employed at the hospitals where the research took place.

Participation in this study was completely voluntary. Before gathering data, the researchers introduced themselves, explained the study aim, and asked prospective participants to review and sign the informed consent. To maintain confidentiality, the names of all parents and hospitals were removed from the collection sheets and replaced by numeric codes. Only the principal investigator held access to the codes.

\section{Data Analysis:}

Data were analyzed using SPSS version 20. Tests for data normality were conducted to the data distribution, and descriptive and Pearson's correlation coefficient tests were applied.

\section{RESULTS AND DISCUSSION}

\section{Results:}

Based on maternal demographic variables, most women with LBW babies in this study were 27-35 years old $(43.3 \%)$, followed by mothers aged 36 and older $(38.3 \%)$; these women are considered to have high-risk pregnancies. The most common maternal education was that of high school graduate (57.7\%). Most mothers were unemployed (70\%), and they had family incomes of less than US\$ 244 per month (76.3\%), which is below the regional minimum wage for Jakarta. Analyses were also performed on infant health concerns during hospitalization, with the following results: the majority of LBW infants experienced temperature instability (71.1\%), followed by respiratory problems (55\%), hyperbilirubinemia (31.6\%), digestive disorders (18.33\%), and infections/sepsis $(16.67 \%)$.

Figure 1 shows that $14 \%$ of mothers surveyed experienced severe stress, and $38 \%$ experienced moderate stress during the discharge process. The most common stresses are: trouble sleeping at night because of worry, feeling lonely and helpless, feeling tired or weak, being scared of doing something wrong to make the baby sick, and worrying about taking care of the baby at home.

In similar study of Patil, (2014) showed slightly different results. Assessing the mothers stress they found $70 \%$ had moderate stress and $30 \%$ had severe stress, while no mothers with mild stress were present.

Fig. 1: Maternal stress level on LBW birth

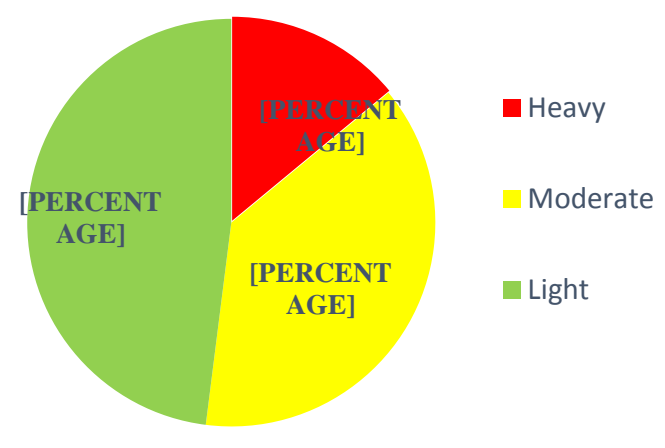

Based on the assessments of mothers' stress levels, we analyzed the coping strategies they reported; they either focus on problem solving or focus on emotions.

The most common coping strategy was problem solving by seeking social support. $78.3 \%$ of this support came from those around mothers, while $51.7 \%$ came from health care workers. The next most-common strategies were solving problems gradually by planning for the LBW infant's care $(55 \%)$ and making a care plan for when the infant came home $(53.3 \%)$ (Table 1$)$. 
Table 1: Distribution of Mothers' Coping Strategies that Focus on Problem Solving

\begin{tabular}{lccccc}
\hline \multicolumn{1}{c}{ Approaching type of coping strategy } & $\begin{array}{c}\text { Never } \\
(\%)\end{array}$ & $\begin{array}{c}\text { Incidentally } \\
(\%)\end{array}$ & $\begin{array}{c}\text { Occasionally } \\
(\%)\end{array}$ & $\begin{array}{c}\text { Frequently } \\
(\%)\end{array}$ & $\begin{array}{c}\text { Always } \\
(\%)\end{array}$ \\
\hline $\begin{array}{l}\text { Step-by-step or planned problem solving } \\
\quad \text { Full of concentration to take care of LBW }\end{array}$ & - & - & $4(6.7)$ & $23(38.3)$ & $33(55)$ \\
$\quad \begin{array}{l}\text { Have a plan for the infant at home later } \\
\text { Confrontative Coping }\end{array}$ & $4(6.7)$ & $4(6.7)$ & $5(8.3)$ & $15(25)$ & $32(53.3)$ \\
$\quad \begin{array}{l}\text { Thinking what mistakes are causing LBW delivery } \\
\text { Disappointed with health workers who did not detect } \\
\text { problems with the infant during pregnancy }\end{array}$ & $2(3.3)$ & $11(8.3)$ & $23(38.3)$ & $8(18.3)$ & $16(26.7)$ \\
$\begin{array}{l}\text { Seeking social support } \\
\quad \begin{array}{l}\text { The people around me pay attention to my baby's } \\
\text { condition }\end{array}\end{array}$ & $7(11.7)$ & $23(38.3)$ & $23(38.3)$ & $3(5)$ & $4(6.7)$ \\
$\quad \begin{array}{l}\text { Get the support of health workers in terms of learning } \\
\text { to treat LBW }\end{array}$ & $6(10)$ & $9(15)$ & $6(10)$ & $8(13.3)$ & $31(51.7)$ \\
$\quad$ Share feelings with people whom I trust & $4(6.7)$ & $11(8.3)$ & $16(26.7)$ & $19(31.7)$ & $10(16.7)$ \\
\hline
\end{tabular}

This confirms the results of Hughes, McCollum, Sheftel, \& Sanchez, (1994) study with the same population, where the largest proportion of maternal coping was accounted for by Seeking Social Support (24\%). Also Seideman et al., (1997) study showed that the parents were found to have coped by using a problem-focused approach by seeking information about their infants' progress from the medical and nursing staff

When we examined deep coping strategies that focus on emotional adjustment, the most common approach was finding positive meaning through prayer $(86.7 \%)$. Mothers were also inspired to seek more information about LBW infants (76.6\%). Another strategy focused on being calm when facing problems associated with the birth and care of the LBW infant at the hospital (71\%) (Table 2).

Table 2: Distribution of Mothers' Coping Strategies that Focus on Emotional Settings

\begin{tabular}{|c|c|c|c|c|c|}
\hline Approaching type of coping strategy & $\begin{array}{c}\text { Never } \\
(\%)\end{array}$ & $\begin{array}{c}\text { Incidentally } \\
(\%)\end{array}$ & $\begin{array}{c}\text { Occasionally } \\
(\%)\end{array}$ & $\begin{array}{c}\text { Frequently } \\
(\%)\end{array}$ & $\begin{array}{c}\text { Always } \\
(\%)\end{array}$ \\
\hline \multicolumn{6}{|l|}{ Self-control } \\
\hline Try to be calm about the current situation & - & - & $5(8.3)$ & $10(16.7)$ & $45(71)$ \\
\hline $\begin{array}{l}\text { Try not to distress others about the condition of the } \\
\text { infant }\end{array}$ & $1(1.7)$ & $10(16.7)$ & $12(20)$ & $19(31.7)$ & $18(30)$ \\
\hline \multicolumn{6}{|l|}{ Distancing } \\
\hline Thinking that having LBW is "destiny" & $4(6.7)$ & $15(25)$ & $20(33.3)$ & $17(28.3)$ & $4(6.7)$ \\
\hline Trying to forget having LBW & - & $36(60)$ & $6(10)$ & $10(16.7)$ & $8(13.3)$ \\
\hline \multicolumn{6}{|l|}{ Positive reappraisal } \\
\hline Got more experience for having LBW & $8(13.3)$ & $15(25)$ & $17(28.3)$ & $14(23.3)$ & $6(10)$ \\
\hline Inspired to find more information about LBW care & $2(3.3)$ & - & $4(6.7)$ & $46(76.7)$ & $8(18.3)$ \\
\hline Pray about the current situation & - & - & - & $52(86.7)$ & $8(13.3)$ \\
\hline \multicolumn{6}{|l|}{ Accepting responsibility } \\
\hline $\begin{array}{l}\text { Promise yourself to seek information about LBW } \\
\text { treatments at all times }\end{array}$ & $4(6.7)$ & - & $11(18.3)$ & $32(33.3)$ & $13(21.7)$ \\
\hline Realize the need to learn actively about LBW care & $2(3.3)$ & $2(3.3)$ & $7(11.5)$ & $32(33.3)$ & $17(28.3)$ \\
\hline \multicolumn{6}{|l|}{ Escape/avoidance } \\
\hline More sleep, since having LBW & $2(3.3)$ & $45(75)$ & $6(10)$ & $3(5)$ & $4(6.7)$ \\
\hline $\begin{array}{l}\text { Try not to worry, by eating or using medication to } \\
\text { sleep }\end{array}$ & $2(3.3)$ & $34(56.7)$ & $6(10)$ & $8(13.3)$ & $10(16.7)$ \\
\hline $\begin{array}{l}\text { Keep away from people who ask about the infant } \\
\text { situation }\end{array}$ & - & $39(65)$ & $13(21.7)$ & - & $8(13.3)$ \\
\hline $\begin{array}{l}\text { Hoping that the situation of having LBW never } \\
\text { happens }\end{array}$ & $2(3.3)$ & $42(70)$ & $10(16.7)$ & $2(3.3)$ & $4(6.7)$ \\
\hline
\end{tabular}

These results are in line with results of the study by Seideman et al., (1997) which showed that the parents use emotion-focused approach by focusing on their infant received proper care. This level of vigilance assisted them in feeling involved in their infants' welfare.

The correlation test uncovered all correlations between stress items and mothers' average coping skills scores when preparing from Perinatology ward discharge (Table 3). Pearson's correlation coefficient showed a moderately negative significant correlation between "I have trouble sleeping at night because of worries about my baby" and mothers' coping strategies $(\mathrm{p}=0.002$; $\mathrm{r}$. -0.389). This means that low coping skills are seen in respondents who report this experience. Furthermore, we found a strong negative significant correlation between two other experiences and mothers' coping strategies: "I was worried about taking care of the baby at home" (p $<0.001$; r. -0.567), and "I am scared I will do something wrong and make the baby sick" (p <0.001; r. -0.667$)$. The more anxious a mother feels about caring for her baby at home, the lower her coping strategy score will be. The more frightened a mother is of making a mistake in caring for the baby at home, the lower her coping score. 
Mothers' coping strategy scores were not significantly correlated with "I feel lonely and helpless" $(p=0.245)$ or "I feel tired/weak" ( $\mathrm{p}=0441)$.

Table 3: Pearson's Correlation between Stress Items and Mothers' Coping Strategies

\begin{tabular}{|c|c|c|c|c|}
\hline Item & Mean & $\begin{array}{l}\text { Standard Deviation } \\
\text { (SD) }\end{array}$ & $\begin{array}{c}\text { Correlation } \\
\text { coefficients (r) }\end{array}$ & $\begin{array}{l}\text { Significance level } \\
(p)\end{array}$ \\
\hline $\begin{array}{l}\text { I have trouble sleeping at night because I } \\
\text { worry about my baby }\end{array}$ & 2.30 & 1.169 & -0.389 & $0.002 *$ \\
\hline I feel lonely and helpless & 4.32 & 1.214 & -0.152 & 0.245 \\
\hline $\begin{array}{l}\text { I was worried about taking care of the } \\
\text { baby at home }\end{array}$ & 3.37 & 1.372 & -0.567 & $<0.001 *$ \\
\hline $\begin{array}{l}\text { I am scared I will do something wrong } \\
\text { and make the baby sick }\end{array}$ & 2.97 & 1.314 & -0.667 & $<0.001 *$ \\
\hline I feel tired/weak & 4.30 & 1.169 & -0.101 & 0.441 \\
\hline
\end{tabular}

*p value $<0.05$

The means and standard deviations of the mothers' stress scores and coping strategy scores were $17.25 \pm$ 3.763 and $56.53 \pm 6.242$, respectively. Based on the Pearson's correlation coefficient, we observed a significant statistical association between mothers' stress and coping scores $(p<0.001)$. The significant correlation coefficient of -0.641 indicates that higher incidences of stress experiences seem to decrease mothers' coping strategy abilities. These variables show a strong relationship (Table 4).

Table 4: Relationship between Mothers' Stress and Coping Strategies

\begin{tabular}{llll}
\multicolumn{1}{c}{ Variables } & Mean & SD & r \\
\hline Mothers' stress scores & 17.25 & 3.763 & -0.641 \\
Mothers' coping strategies scores & 56.53 & 6.242 & $<0.001^{*}$ \\
\hline
\end{tabular}
*p value $<0.05$

We conducted an analysis to determine the factors that influence improvements in mothers' coping strategy scores based on their demographics and the LBW infants' characteristics. An evaluation of the relationship between family income and mothers' coping strategies using independent $t$-tests showed no statistically significant relationship between these variables. Furthermore, the relationship between a history of infant health problems and the mother's coping strategies score also showed no statistically significant relationship; however, there was a significant statistical association between a history of hyperbilirubinemia and mothers' coping strategy scores $(\mathrm{p} .=0.007)$. Thus, mothers of infant with a history of hyperbilirubinemia showed more stress than others. The mean coping strategies scores of mothers whose infants had hyperbilirubinemia were significantly lower than those with no history of the condition (Table 5).

Reid et al (2007) study was similar to the present one; they reported a significant relationship between the infant's health statuses in the NICU. Mothers whose LBW infant have a history of hyperbilirubinemia perceived greater stress about taking their infants home than those without such a history. Concern about the recurrence of the hyperbilirubinemia significantly reduced their coping scores. Hyperbilirubinemia in LBW infants can disrupt their weight gain targets, as the condition affects the stimulation for breastfeeding.

Table 5: Relationship between Mothers' Demographics and Characteristics of LBW Infants with Mothers' Coping Strategies Using Independent T-test

\begin{tabular}{|c|c|c|c|}
\hline Variables & Mean & $\mathrm{SD}$ & $p$ \\
\hline \multicolumn{4}{|l|}{ Mothers' Demographics } \\
\hline Family Income (per month) & & & 0.831 \\
\hline$<\mathrm{US} \$ 244$ & 56.65 & 5.610 & \\
\hline$\geq \mathrm{US} \$ 244$ & 56.14 & 8.226 & \\
\hline \multicolumn{4}{|l|}{ Infants' Health Problems } \\
\hline \multicolumn{4}{|l|}{ History } \\
\hline Respiratory Problems & & & 0.221 \\
\hline Yes & 55.64 & 6.614 & \\
\hline No & 57.63 & 5.685 & \\
\hline Temperature instability & & & 0.798 \\
\hline Yes & 56.20 & 6.161 & \\
\hline No & 56.79 & 6.614 & \\
\hline Hyperbilirubin & & & $0.007 *$ \\
\hline Yes & 52.34 & 5.166 & \\
\hline No & 57.71 & 6.149 & \\
\hline Digestive Disorders & & & 0.592 \\
\hline Yes & 57.45 & 6.283 & \\
\hline No & 56.33 & 6.280 & \\
\hline Infection / Sepsis & & & 0.270 \\
\hline Yes & 53.10 & 4.041 & \\
\hline No & 57.12 & 6.365 & \\
\hline
\end{tabular}


The relationships between the demographic variables of mothers' education levels, occupation, and age and the mean score of the mothers' coping strategies using the ANOVA test were not significant (Table 6).

These results are in line with results of the study by Ghorbani, Dolatian, Shams, Alavi-Majd, \& Tavakolian, (2014) which showed that maternal age, education, household income, and mother's job were not significantly associated with coping strategies.

Table 6: The Relationship between Participants' Demographics and Mothers'Coping Strategies using the Anova Test

\begin{tabular}{|c|c|c|c|}
\hline Variables & Mean & SD & $p$ \\
\hline Junior High School & 57.08 & 5.937 & \\
\hline College/University & 50.40 & 0.894 & \\
\hline Mother's Employment Status & & & 0.704 \\
\hline Employed & 58.00 & 5.696 & \\
\hline Maternal Age (in years) & & & 0.361 \\
\hline $16-26$ & 58.36 & 8.488 & \\
\hline $27-35$ & 56.92 & 5.366 & \\
\hline $36-\geq 45$ & 53.22 & 5.946 & \\
\hline
\end{tabular}

The correlation test was performed to uncover any correlation between variables of LBW infants' characteristics and the mean scores of mothers' coping strategies (Table 7). The results showed a moderately negative significant correlation between the mother's coping strategy and length of hospitalization ( $p=0.024$; r. 0.291). The longer the infant was hospitalized, the lower the mother's coping strategy score. Birth weight $(\mathrm{p}=0.311)$ and gestational age $(\mathrm{p}=0.334)$ were not significantly correlated with mothers' coping strategy scores.

Table 7: Pearson's Correlation of Characteristics of LBW Infants With Mothers' Coping Strategies

\begin{tabular}{lcccc}
\hline \multicolumn{1}{c}{ Variables } & Mean & SD & r & $p$ \\
\hline Birth weight & 1968.7 & 391.402 & -0.133 & 0.311 \\
Gestational age & 33.90 & 31.39 & 0.334 & 0.334 \\
Length of hospitalization & 4.57 & 3.70 & $-0,291$ & $0.024^{*}$ \\
\hline
\end{tabular}

*p value $<0.05$

Based on Segre's research (2015), revealed that babies' health problems occurring in the first two weeks of hospitalization are a significant factor affecting parental depression. A lengthy hospital stay may generate medical or psychosocial complications, including higher family's expenses for hospital fare and risk of infection. The longer an infant is admitted in intensive care unit, the higher parent's stress level (Reid et al. 2007; Shaw et al. 2013). Creating Opportunities for Parent Empowerment (COPE) Program, which was developed by Melnyk and colleagues (2006), reported that involving family since early hospitalization may shorten LBW infant's length of stay. A group of infant provided with COPE program had a shorter length of stay at NICU compared to those who were not provided with this program. It indicated that the shorter infant's length of stay would promote mother's coping skill and adaptation.

\section{Discussion:}

The results showed that lower stress scores are significantly associated with better uses of coping strategies. Higher stress scores equal lower maternal coping abilities. These findings show that "worrying about taking care of the infant at home" and "being scared of doing something wrong to make the baby sick" significantly and negatively affect the mothers' coping strategies.

Discharge from the intensive care unit is a moment of mixed feelings. Going home is a happy event, but one combined with parental anxiety (Raines, 2013). Preterm infants usually require additional care and support post-discharge, because of health and developmental problems related to their immaturity (Hutchinson, Spillet, $\&$ Cronin, 2012). Further, factors that cause parental stress about bringing the infant home inhibit the bonding process (Aagaard et al., 2015; Browne and Talmi, 2005); these include high medical needs, the length of hospitalization, and a lack of knowledge about the infant's condition and development (Patil, 2014; Segre et al., 2015). Olshtain-Mann \& Auslander (2008) have also reported on the ongoing stress after returning home. They found that parents of preterm newborns still experienced higher levels of stress and lower levels of competence when compared to parents of full-term infants even two months after discharge. Schappin et al (2013) metaanalysis however, concluded that, in contrast to these data and the current study, the stress experienced by parents of preterm infants was only somewhat higher than that experienced by parents of term newborns. Nevertheless, mothers should be cautious about the incidence of post-traumatic stress after bringing their babies home. Parents who perceived stress from the beginning and developed post-traumatic stress are more likely to 
employ avoidance as a coping mechanism and to act passively when obtaining information on care for their infants. By modifying these maladaptive responses, post-traumatic stress can be prevented (Shaw et al., 2013).

Mothers, need personal and environmental support to develop coping strategies (Boykova \& Kenner, 2012). Developing a mother's coping and self-care strategies is important for the infant's long-term well-being and development, and for the integrity of the family unit. Mothers' coping strategies are associated with parental stress, and those with maladaptive coping mechanisms experience greater psychological pressure (Gangi et al., 2013). Older individuals with low levels of anxiety and high confidence in their ability tend to use problemfocused coping strategies. Conversely, those with high levels of anxiety and depression prefer emotion-focused coping strategies over problem-focused ones (Herman \& Tetrick, 2009). Though we found no significant correlation between maternal stress and coping mechanisms, $86 \%$ of participants employed an emotion-focused approach. One of the most influential factors for promoting a constructive coping strategy is parental involvement in care (Melnyk et al., 2006). We found that more than $50 \%$ of mothers planned to focus on caring for their infants and required support from healthcare providers to achieve this; therefore, nurses play an essential role in providing emotional support for parents. A good relationship between a nurse and his or her patient reduces maternal stress. Hasanpour, Alavi, Azizi, \& Als, (2017) study showed the importance of nurseparent communication and the frequency of communication between nurses and parents in reducing NICU parents' stress. Parents' frequent contact with their infants appears to be vitally effective for reducing parent stress. Delivering accurate and clear information, and involving parents in the infant's care, allowed parents to feel supported and enhanced their self-efficacy to care for the infant upon discharge (Patil, 2014; Raines, 2013).

This study also revealed that $78 \%$ of mothers' coping strategies were developed because of family support. Family members can help reduce stress related to caring for LBW infant at home. Family empowerment improves parents' ability to care the infant and affects infants's health (Browne and Talmi, 2005; Hwang et al., 2013; Melnyk et al., 2009; Rustina et al., 2014). As part of the discharge planning process, nurses should assess how family support can be used to meet the needs of infants and mothers. This is especially important for mothers with high levels of stress related to dealing with NICU infants (Zanardo et al., 2003). As part of an individualized discharge-planning process, nurses might explore how family support can help meet the infant's multiple needs and to allow the mother opportunities for rest. Although one family member, frequently the father, is often involved in the discharge teaching, identifying other helpers early in the discharge process allows them to participate in training activities and to learn about the infant's special needs (Ahn and Kim, 2007; Raines, 2013).

Involving family and supportive others in caregiving prior to discharge may enhance mothers' confidence and willingness to be active participants in the everyday process of meeting the infant's needs and provide her with options for taking time to care for herself. It is clear that family support affects a mother's ability to control herself, especially in the current situation.

The involvement of people around the mother and nurses' support facilitate mothers' abilities to develop coping skills, to control stressful situations, and solve problems. Parents' emotional readiness to bring the infant home is important, and opportunities for active and proactive learning experiences about caring for LBW infant build mothers' confidence (Ahn and Kim 2007; Committee on Fetus and Newborn 2008; Gooding et al. 2011).

\section{Conclusion:}

The purpose of this study was to appraise mothers' coping strategies for dealing with the stresses of discharge preparations for LBW infant. The result showed that level of stress are significantly associated with coping strategies. The higher the stress, the lower a mother's coping abilities. Most mothers used coping strategies that focus on emotional support, rather than solving problems. In this study, when mothers were asked to describe which strategy was used, they reported using more emotion focused coping strategies than problem focused strategies to deal with their experience of having a low birth weight infant. This indicated that perceptions of negative emotions dominated, even though they did not appear to believe they were 'doing anything.

Nurses play an essential role in providing emotional support for parents, so interventions must be developed to help mothers develop coping strategies by focusing on problem solving through family involvement and education about LBW infants' care. Many mothers are better able to cope with the stress of having a LBW infant in the perinatology ward when they take an active part in the care of their infants before discharge. Mothers should be able to provide basic care for LBW infant, such as kangaroo care, exclusive breastfeeding, bathing, and temperature monitoring. They also should be able to recognize the danger signs in infants, the early symptoms of dangerous diseases, and how to manage them. This allows them to feel useful and, importantly, to gain experience in the handling of their tiny infant. Encouraging mothers to accept responsibility by getting involved in their infant's care will improve the mothers' coping skill and make them feel confident and competent to care for her infant at discharge. Although it is difficult to empower mothers or parents during the hospitalization period, it is important to do so. From the beginning, they should be encouraged, to the extent possible, to touch, and speak to their baby. 
Limitations of this study, research was only addressed stress and coping strategies for mothers whose infants were admitted to perinatology ward. Also, include the limitation of sample size. A strength of this study was both perinatology wards implemented similar discharge planning process. Also, comparing and contrasting parents in the two perinatology wards was the same time, with use of the same research methodology.

\section{Future Scope:}

The findings from this study suggest possible implications for clinical care. First, although mothers assume full responsibility for their infant's care following discharge, many do not feel fully prepared for this role when they take their infant home. This situation causes stress on the mother. Mothers must deal with stress by developing problem-focused coping strategies. The results of this study suggest that mothers should be taught how to accept responsibility and regain a sense of control over the stressful situation. Nurses should assist mothers to develop coping strategies that focus on problem solving as part of discharge planning by involving families and providing LBW infant care education. Support and educate parents should be done during their infant's hospitalization and continued on the infant's discharge home.

Second, nurses should have an education about the concept of stress and certain coping strategies on that basis they have to provide information to the mothers of LBW infant. Nurse's challenge is to continue to expand their knowledge so they can support and enhance parents' efforts to manage stress in such a way that the parentinfant relationship is nurtured. Nurses also have a role in facilitating effective communication with parents. By using their listening and interviewing skills, can identify the needs and concerns of the parents.

Third, further research is needed to determine the impact of health education on LBW infant care on mothers during hospitalization to improve maternal coping skills. An experimental studies can be done to see the effectiveness of educational programs on the development of maternal coping strategies. Another study is to assess the mother's ability to care for LBW infant at home after discharge from hospital. This research is highly recommended to do because of the inability of mother and family to take care LBW infant at home will have an impact on rehospitalization.

\section{ACKNOWLEDGMENTS}

The authors would like to thank the Ministry of Research, Technology and Higher Education of the Republic of Indonesia and the Directorate of Research and Community Service, Indonesia University, which funded this study through a 2017 Competency-Based Research Grant. Our appreciation is also extended to the Directors of the Maternal and Child Hospital of Budi Kemuliaan and Tarakan General Hospital, in Central Jakarta, for giving us permission to conduct the study.

\section{REFERENCES}

Aagaard, H., L. Uhrenfeldt, M.S. Ludvigsen, L. Fegran, 2015. Parents' experiences of transition when their infants are discharged from the Neonatal Intensive Care Unit: a systematic review protocol. The JBI Database of Systematic Reviews and Implementation Reports, 13(10): 1-7. https://doi.org/10.11124/jbisrir-2015-2287

Agrawal, R., A. Gaur, 2017. Parent stress in neonatal intensive care unit: an unattended aspect in medical care. International Journal of Contemporary Pediatrics, 4(1): 148-153. https://doi.org/10.18203/23493291.ijcp20164596

Ahn, Y.M., N.H. Kim, 2007. Parental Perception of Neonates, Parental Stress and Education for NICU Parents. Asian Nursing Research, 1(3): 199-210. https://doi.org/10.1016/S1976-1317(08)60022-5

Altimier, L., R.D. White, 2014. The Neonatal Intensive Care Unit (NICU) Environment. In C. Kenner \& Judy Wright Lott (Eds.), Comprehensive Neonatal Nursing care (Fifth Edit, pp: 722-762). New York: New York: Springer Publishing Company.

Boykova, M., C. Kenner, 2012. Transition From Hospital to Home for Parents of Preterm Infants. The Journal of Perinatal \& Neonatal Nursing, 26(1): 88-89. https://doi.org/10.1097/JPN.0b013e318248b20c

Browne, J.V., A. Talmi, 2005. Family-Based Intervention to Enhance Infant - Parent Relationships in the Neonatal Intensive Care Unit. Journal of Pediatric Psychology, 30(8): 667-677. https://doi.org/10.1093/jpepsy/jsi053

Committee on fetus and newborn, 2008. Hospital Discharge of the High-Risk. Pediatrics, 122(5): 11191126. https://doi.org/10.1542/NICU

Folkman, S., R.S. Lazarus, 1985. If it changes it must be a process: Study of emotion and coping during three stages of a college examination. Journal of Personality and Social Psychology, 48(1): 150-170. https://doi.org/10.1037/0022-3514.48.1.150

Gangi, S., D. Dente, E. Bacchio, S. Giampietro, G. Terrin, M. De Curtis, 2013. Posttraumatic Stress Disorder in Parents of Premature Birth Neonates. Procedia - Social and Behavioral Sciences, 82(2013): 882885. https://doi.org/10.1016/j.sbspro.2013.06.365

Ghorbani, M., M. Dolatian, J. Shams, H. Alavi-Majd, S. Tavakolian, 2014. Factors associated with 
Posttraumatic Stress Disorder and Its Coping Styles in Parents of Preterm and Full-Term Infants. Global Journal of Health Science, 6(3), 65-73. https://doi.org/10.5539/gjhs.v6n3p65

Gigante, D.P., C.G. Victora, H. Gonçalves, R.C. Lima, F.C. Barros, K.M. Rasmussen, 2004. Risk factors for childbearing during adolescence in a population-based birth cohort in southern Brazil. Revista Panamericana de Salud Pública, 16(1): 1-10. https://doi.org/10.1590/S1020-49892004000700001

Gooding, J.S., L.G. Cooper, A.I. Blaine, L.S. Franck, J.L. Howse, S.D. Berns, 2011. Family Support and Family-Centered Care in the Neonatal Intensive Care Unit: Origins, Advances, Impact. Seminars in Perinatology, 35(1): 20-28. https://doi.org/10.1053/j.semperi.2010.10.004

Hasanpour, M., M. Alavi, F. Azizi, H. Als, 2017. Iranian parent - staff communication and parental stress in the neonatal. Journal of Education and Health Promotion, 6: 1-7. https://doi.org/10.4103/jehp.jehp

Herman, J.L., L.E. Tetrick, 2009. Problem-focused versus emotion-focused coping strategies and repatriation adjustment. Human Resource Management, 48(1): 69-88. https://doi.org/10.1002/hrm.20267

Hughes, M., J. McCollum, D. Sheftel, G. Sanchez, 1994. How Parents Cope With the Experience of Neonatal Intensive Care. Children's Health Care, 23(1): 1-14. https://doi.org/10.1207/s15326888chc2301_1

Hutchinson, S.W., M.A. Spillet, M. Cronin, 2012. Parents ' Experiences during their Infant ' s Transition from Neonatal Intensive Care Unit to Home: A Qualitative Study. The Qualitative Report, 17(12): 1-20. Retrieved from http://nsuworks.nova.edu/tqr/vol17/ iss12/1\%0AThis

Hwang, S.S., D. Wanda, R.A. Smith, B. Morrow, C.K. Shapiro-mendoza, C.B. Prince, M.C. McCormick, 2013. Discharge Timing, Outpatient Follow-up , and Home Care of Late-Preterm and Early-Term Infants. Pediatrics, 132(1): 101-108. https://doi.org/10.1542/peds.2012-3892

Jefferies, A.L., 2016. Going home : Facilitating discharge of the preterm infant. Paediatr Child Health, 19(1): 31-36. 37.

Kenner, C., J.W. Lott, 1990. Parent transition after discharge from the NICU. Neonatal Network, 9(2): 31http://www.ncbi.nlm.nih.gov/entrez/query.fcgi?cmd=Retrieve\&db=PubMed\&dopt=Citation\&list_uids=2392114

Klebanov, P.K., J. Brooks-Gunn, M.C. McCormick, 2001. Maternal coping strategies and emotional distress: Results of an early intervention program for low birth weight young children. Developmental Psychology, 37(5): 654-667. https://doi.org/10.1037//0012-1649.37.5.654

Melnyk, B.M., H.F. Crean, N.F. Feinstein, E. Fairbanks, 2009. Maternal anxiety and depression following a premature infants' discharge from the NICU: Explanatory effects of the COPE program. Nursing Research, 57(6): 383-394. https://doi.org/10.1097/NNR.0b013e3181906f59.Maternal

Melnyk, B.M., N.F. Feinstein, L. Alpert-Gillis, E. Fairbanks, H.F. Crean, R.a Sinkin, S.J. Gross, 2006. Reducing premature infants' length of stay and improving parents' mental health outcomes with the Creating Opportunities for Parent Empowerment (COPE) neonatal intensive care unit program: a randomized, controlled trial. Pediatrics, 118(5): e1414-e1427. https://doi.org/10.1542/peds.2005-2580

Miquel-Verges, F., P.K. Donohue, R.D. Boss, 2011. Discharge of infants from NICU to latino families with limited english proficiency. Journal of Immigrant and Minority Health, 13(2): 309-314. https://doi.org/10.1007/s10903-010-9355-3

Nicolson, S., F. Judd, F. Thomson-Salo, S. Mitchell, 2013. Supporting the adolescent mother-infant relationship: preliminary trial of a brief perinatal attachment intervention. Archives of Women's Mental Health, 16(6): 511-520. https://doi.org/10.1007/s00737-013-0364-9.

Olshtain-Mann, O., G.K. Auslander, 2008. Parents of preterm infants two months after discharge from the hospital: are they still at (parental) risk? Health \& Social Work, 33(4): 299-308, 10 https://doi.org/10.1093/hsw/33.4.299

Patil, S., 2014. Level of Stress and Coping Strategies Seen Among Parents of Neonates. International Journal of Science and Research, 3(4), 579-585. Retrieved from www.ijsr.net

Raines, D.A., 2013. Preparing for NICU Discharge: Mothers' Concerns. Neonatal Network: The Journal of Neonatal Nursing, 32(6): 399-403. https://doi.org/10.1891/0730-0832.32.6.399

Ray, K., G.J. Escobar, S.A. Lorch, 2010. Premature infants born to adolescent mothers: Health care utilization after initial discharge. Academic Pediatrics, 10(5): 302-308. Retrieved from http://ovidsp.ovid.com/ovidweb.cgi?T=JS\&PAGE=reference\&D=emed9\&NEWS=N\&AN=2010485685

Reichman, S.R.F., A.C. Miller, R.M. Gordon, K.D. Hendricks-Munoz, 2010. Stress Appraisal and Coping in Mothers of Nicu Infants. Children's Health Care, 29(4): 279-293. https://doi.org/10.1207/S15326888CHC2904

Reid, T., R. Bramwell, T. Reid, R. Bramwell, N. Booth, M. Weindling, 2007. Perceptions of parent - staff communication in Neonatal Intensive Care: The findings from a rating scale Perceptions of parent e staff communication in Neonatal Intensive Care: The findings from a rating scale. Journal of Neonatal Nursing, 13: 64-74. https://doi.org/10.1016/j.jnn.2007.01.004

Rustina, Y., A.Y. Nursasi, T. Budiati, E. Syahreni, P. Fitriyani, 2014. Pengaruh pemberdayaan keluarga terhadap status kesehatan bayi berat lahir rendah di kota Jakarta. Makara J, Health Res, 18(1): 19-24. 
https://doi.org/10.7454/msk.v18i1.3089

Schappin, R., L. Wijnroks, M.M.A.T.U. Venema, M.J. Jongmans, 2013Rethinking Stress in Parents of Preterm Infants: A Meta- Analysis. PloS One, 8(2): e54992-e54992. https://doi.org/10.1371/journal.pone.0054992

Segre, L.S., J.E. McCabe, R. Chuffo-Siewert, M.W. O’Hara, 2015. Depression and Anxiety Symptoms in Mothers of Newborns Hospitalized on the Neonatal Intensive Care Unit. Nurs Res. 2014, 63(5): 320-332. https://doi.org/10.1097/NNR.0000000000000039.Depression

Seideman, R.Y., M.a. Watson, K.E. Corff, P. Odle, J. Haase, J.L. Bowerman, 1997. Parent stress and coping in NICU and PICU. Journal of Pediatric Nursing, 12(3): 169-77. https://doi.org/10.1016/S08825963(97)80074-7

Shaw, R.J., R.S. Bernard, A. Storfer-Isser, W. Rhine, S.M. Horwitz, 2013. Parental Coping in the Neonatal Intensive Care Unit. Journal of Clinical Psychology in Medical Settings, 20(2): 135-142. https://doi.org/10.1007/s10880-012-9328-X

Welch, M.G., M.S. Halperin, J. Austin, R.I. Stark, M.A. Hofer, AA. Hane, M.M. Myers, 2016. Depression and anxiety symptoms of mothers of preterm infants are decreased at 4 months corrected age with Family Nurture Intervention in the NICU. Archives of Women's Mental Health, 19(1): 51-61. https://doi.org/10.1007/s00737-015-0502-7

Zanardo, V., F. Freato, F. Zacchello, 2003. Maternal anxiety upon NICU discharge of high-risk infants. Journal of Reproductive and Infant Psychology, 21(1): 69-75. https://doi.org/10.1080/0264683021000060093 